\title{
Examining stress and coping: Program improvements of pre-licensure nursing students
}

\author{
Krysia W. Hudson*1, George R. Kim², Grace T. Osipowicz ${ }^{1}$, Nicole L. Mollenkopf ${ }^{1}$, Nikki E. Akparewa ${ }^{3}$, Marion J. \\ Ball $^{1}$ \\ ${ }^{1}$ School of Nursing, Johns Hopkins University, United States \\ ${ }^{2}$ School of Public Health, Johns Hopkins University, United States \\ ${ }^{3}$ Transform Nursing, United States
}

Received: May 2, 2019

Accepted: June 20, 2019

Online Published: June 26, 2019

DOI: $10.5430 /$ jnep.v9n9p131

URL: https://doi.org/10.5430/jnep.v9n9p131

\begin{abstract}
In a pre-licensure program, an unexpected number of episodes of student distress occurred during clinical training (resulting in emergency department visits and health-related absenteeism) in the first semester. To understand the underlying reasons for these episodes, investigators retrospectively explored how these students perceived and approached the stresses associated prior to and after their first semester work (as a part of program to improve performance and student well-being). Program innovations were employed, and student distress has dramatically decreased.
\end{abstract}

Key Words: Nursing student, Student stress, Coping

\section{INTRODUCTION}

Nursing is a profession that is highly rewarding, and places high demands of its practitioners, both externally and internally. Nurses complete stringent requirements for training and licensure. Practitioners must practice with the highest integrity with low tolerances for performance errors and high thresholds for details, all of which can be sources of stress.

The academic path of nursing students is intense, and students are burdened with stressors. Students commonly reflect that nursing school impacts many areas of their lives like exercise, diet, sleep and social life. Students must successfully adapt to reach professional and personal maturity in becoming a licensed bedside nurse. Stress can come from many different venues. Some studies indicate that initial training is considered stressful, due to self-perceived knowledge/skill deficits and new types of workloads. ${ }^{[1,2]}$ Other studies indicate that it is challenging to develop relationships with clients, teachers and colleagues. ${ }^{[3,4]}$ Clinical assignments, compounded with patient suffering and patient deaths, also contribute to student stress. ${ }^{[5,6]}$ Some studies also indicated that clinical provided positive or "eustress" as well. ${ }^{[7,8]}$

In light of the studies highlighting the stress impacting students, other studies have described nursing student distress and coping mechanisms. ${ }^{[9-11]}$ When students cannot manage or adapt to stress successfully, they may experience physical and psychological impairment that may impede performance. ${ }^{[12]}$ With an eye to retaining nurses and nurse trainees, there is growing professional interest in assessing and assuring their well-being. ${ }^{[10,13-18]}$ as well as providing tools for self-management. Therapies that have been de-

\footnotetext{
*Correspondence: Krysia W. Hudson; Email: khudson2@jhu.edu; Address: Department of Acute and Chronic Care, School of Nursing, Johns Hopkins UNiversity, United States.
} 
scribed include: art expressive therapy, ${ }^{[10]}$ self-care, leveraging the "protective nature of inner resources"[18] and massage therapy. ${ }^{[17]}$ Additionally, there is a movement towards the growth and formalization of "Self-Care" curricula in nursing education at all levels ${ }^{[13,14]}$ with multi-level programs for students that focus on healthy eating, stress management and support-seeking. Considering the literature surrounding novice nursing students, the investigators wanted to identify the underlying cause of student illness during first semester clinical and identify the coping mechanisms surrounding this phenomenon.

\section{Case Presentation}

\subsection{Program innovation}

It is not enough to assume that students can "figure it out" as they become practitioners. Instead, the clinical faculty employed a toolkit to decrease student stress. The American Holistic Nurses Association ${ }^{[19]}$ and American Nurses Association $^{[20]}$ recommends stress management techniques for nursing students. In fact, the $\mathrm{ANA}^{[20]}$ covered topics to enhance nurse health such as: combating stress, healthy sleep, nutrition, and work-life balance. Didactic discussion of stress reduction techniques is not enough. Infusion of coping strategies should be employed. ${ }^{[14,16,21,22]}$ After consulting with clinical faculty, change was necessary to decrease student stress in clinical in the first semester clinical course. A stress reduction toolkit has been implemented in this first semester course. The content is covered, practiced and outlined in class and practical manifestation is supported and reinforced in clinical. The toolkit included the following stress reduction components: deep breathing (6 second breath), mindful eating, guided imagery, self-care and reflection.

These interventions are designed to incorporate quick stress reduction techniques that students can employ in clinical, post conference and during the week to help reduce stress of the nursing student. The first component, deep breathing, incorporated the 6 second breath. Deep breathing (e.g. 6 second breath) is practiced in class and can be employed at any time. The usefulness of this technique is profound and many phone apps have been created to be employed in the wider population: Breath2Relax, Pranayama, Paced Breathing, Relax Stress and Anxiety Relief, Prana Breath and Anxiety Zone. ${ }^{[23]}$ Deep breathing has been found to be a successful stress reduction technique as found in several studies. ${ }^{[24,25]}$ A study ( $\mathrm{n}=20$ nursing students) implementing deep breathing exercises and a stress-reducing workshop to reduce the nursing students' stress levels to increase perception of quality patient care discovered that students stress levels were decreased and their perception of quality patient care improved after utilizing the stress-reducing interven- tions. ${ }^{[26]}$ Principally, these studies warrant more exploration; in particular, studying how these interventions would affect nursing students when implemented early in their curriculum and utilized throughout their respective programs.

Mindful eating is the second technique that was taught and employed. Students are encouraged to sit and take a piece of food (preferably something that melts) and let the food melt in their mouth. While doing this, they are encouraged to deep breathe. This technique can be incorporated during student breaks. Mindful eating is a technique endorsed by AHNA. ${ }^{[19]}$ A literature review reviewing mindfulness, mindful eating, and intuitive eating in changing eating behaviors found that being mindful in general, "appears to work by an increased awareness of internal, rather than external, cues to eat. Mindfulness-based approaches may prevent weight gain and encouraging a mindful-eating approach would seem to be a positive message to be included in general weight management advice to the public."[27] Principally, nursing students should take an increased awareness of their internal state and be mindful of what they are eating, especially due to a rigorous clinical workload.

Guided imagery is another specific technique discussed in class and encouraged in clinical. This intervention, as created by one of the authors, allows for a student to leave the source of stress- leaving the clinical unit for a few minutes. The student excuses themselves to the bathroom, closes their eyes and washes their hands for a count of 10 , while also practicing deep breathing. This activity should help restore balance during the clinical day. One study by Barbara Speck $^{[28]}$ showed that guided imagery used on first semester nursing students $(n=26)$ performing their first intramuscular injections showed, "statistically significant lower levels in anxiety by self-report ( $p=.008)$ ". The significant findings of this study promote the use of guided imagery early on in hope of benefitting students throughout their programs.

Physical self-care is another strategy explored in class. Nutritionally, students often report eating breakfast prior to 5 am and are unable to eat again until lunchtime. To avoid illness and hypoglycemia, students are encouraged to pack plan and consume a small breakfast snack and another midmorning snack. Hydration is something that is encouraged as well. Instructors called these breaks "wellness breaks". Each student is encouraged to take a mandatory 10-minute break during their clinical day to rest, refresh, hydrate, regroup etc. Sleep is discussed in class and appropriate rest is encouraged. As per Spivey, ${ }^{[29]}$ a recommended 7 hours of sleep is considered sufficient to prevent weight gain and maintain a state of health.

Lastly, reflection, as a form of self-awareness, is provided 
informally in post-conference on clinical days. Formal reflection takes place via clinical journaling and students independently reflect on their clinical experiences via a discrete online forum. Organization, in the form of the Clinical Notes Sheet, is utilized daily by all students in clinical. This sheet allows the students to incorporate patient care, and self-care while on the clinical unit. Please see Appendix A for the formal Stress Reduction Toolkit for Student Nurses.

Since incorporation of Stress Reduction Toolkit for Student Nurses in the first semester, only three students have had to leave clinical (in the first semester) due to illness over the past three years. This is a dramatic decrease from previous semesters. Since a decrease was noted, investigators questioned those students that did not have the program innovation (Stress Reduction Toolkit) to understand coping mechanisms applied before the program innovation.

\subsection{Analysis of student stress}

Within this training program, the Clinical Coordinator (CC) oversees the nursing students assigned to approximately 2024 affiliated worksites that are under the supervision of a clinical instructor (CI). This CC is also the theory coordinator (TC) responsible for didactic training (during the first semester), safety and professional conduct of students at the worksites. All clinical worksites are evaluated and chosen by the CC. The CIs, hired by the CC, directly supervise and train students while providing weekly feedback and communication on student progress. Any student illness, problem or issue is handled as soon as possible by course faculty (CI and/or CC).

Historically, students have reported that the first semester is hard. Over the previous years, the CC has noted that several students have had to leave clinical due to illness. As mentioned prior, the aim of this study was to investigate how students coped with stress, as perceived by the student, in a cohort of students that did not have the program innovation addressing stress in the first semester.

\subsubsection{Design}

A qualitative exploration using thematic analysis was adopted for this study. This method offers an open-ended format to capture events in everyday terms of the nursing students. Qualitative studies are a powerful research tool that offer thematic analysis with rich and detailed data. ${ }^{[30]}$

\subsubsection{Sample/participants and recruitment}

This study protocol was approved by the Johns Hopkins University School of Nursing and Johns Hopkins University Institutional Review Boards prior to data collection, with assurances of confidentiality provided to all participants.

The study sample was drawn from a convenience sample Published by Sciedu Press of nursing students in the prelicensure program. Students entering their last semester of pre-licensure nursing school were included. Students involved in creating the JHUSON Stress Toolkit were excluded from the study $(n=1)$. Respondents were recruited voluntarily via group e-mail (one initial email and follow up reminders) with a link to the survey. Response was anonymous, with 36 of 143 students (25.2\%) completing a survey. Under the guidance of nursing school leadership, and the sensitivity of student data, no data was collected on other respondent demographics. Informed consent, with opt-out at any point, of the data collection. The online capture of responses occurred over a two-month period after the students' first year, which allowed capture of their (retrospective) insights with respect over time.

\subsubsection{Data collection}

The survey was deployed on a Qualtrix 2017 system and consisted of five questions to which respondents entered answers through an online interface. The collected data was encrypted and stored securely on the university implementation of Qualtrix. No personal identifiers were requested or retained. Collected data was exported to F4Analyze $\AA 2017$ for analysis.

\subsubsection{Survey design}

Respondents provided short (memo) text answers to three questions and Yes/No to two of the five questions. Three questions asked how the students coped with stress a) prior to nursing school, b) during the first semester clinical rotation, and c) in later semesters (during clinical rotations). Two questions (Yes/No) asked if they had missed clinical time (due to health reasons) during the first semester and if they missed clinical time in later semesters due to health reasons.

\subsubsection{Data analysis}

The online data was downloaded to two members of the research team. A thematic analysis approach was undertaken by the team members were analyzed using Braun and Clarke $^{[30]}$ method of content analysis by two researchers independently. Investigators reviewed the data separately, became familiar with the data. Initial themes were developed after reading the data several times. Next, the investigators searched for themes, reviewed themes and established consensus. Supportive quotations were extracted to add credence to the findings (see Tables 1-4).

\subsubsection{Validity and reliability}

To examine the credibility of the results, the data and themes were shared with a focus group of surveyed students. The focus group acknowledged and agreed with the presented themes as reflecting their own experiences within the context of their training. ${ }^{[31]}$ 


\section{FINDINGS}

\subsection{Reported coping with stress before nursing school}

Before Nursing School, most respondents reported exercise and "socializing" (described as meeting with friends, family and other individuals) as ways of dealing with stress, with many $(\mathrm{n}=33,91.6 \%)$ indicating exercise as principal or frequent coping mechanism. One student indicated:

I exercise to cope with stressors in my life.

Other respondents $(\mathrm{n}=24,66.7 \%)$ indicated "socializing" ("talking to family or friends", "going out") with "family" often cited as a support system. One student indicated:

I also talked to my family and closest friends when I'm stressed.

Another common activity was quiet reflection/meditation (n $=14,38.9 \%$ ) "reading"," taking time to relax" or complementary activities like "meditation" (explicitly mentioned by one student). Self-care activities were mentioned which included "cooking and eating" $(\mathrm{n}=10,27.8 \%)$ and "sleeping" $(\mathrm{n}=$ $6,16.7 \%)$. Prior to nursing school, students mentioned that the use of media ( $n=7,19.4 \%$ ), like watching television, movies or playing video games helped them cope. Interestingly, students also remarked that coping took the form in creating balance with their life $(n=6,16.7 \%)$. One student remarked that they cope via:

Balancing time between work and having fun.

Table 1. Emergent themes: Coping strategies used prior to nursing school $(\mathrm{n}=36)$

\begin{tabular}{lll}
\hline \multirow{2}{*}{ Theme } & \multicolumn{2}{l}{$\begin{array}{l}\text { Number of Participants } \\
\text { Mentioned Theme (\%) }\end{array}$} \\
\cline { 2 - 3 } & $\mathbf{N}$ & $\mathbf{\%}$ \\
\hline Exercise & 33 & 91.6 \\
Socializing & 24 & 66.7 \\
Quiet Reflection/Meditation & 14 & 38.9 \\
Cooking/Eating & 10 & 27.8 \\
Acceptance/Awareness/Balance & 6 & 16.7 \\
Media & 7 & 19.4 \\
Sleep & 6 & 16.7 \\
\hline
\end{tabular}

\subsection{Reported coping with stress during the first semester clinical}

For the first semester, most respondents reported coping with stress "by talking to classmates, instructors and advisors" (not friends and family) $(\mathrm{n}=19,52.8 \%)$. From respondents who cited classmates, advisors and instructors as a stresscoping resource, comments reinforced the importance of these people:

I had a very strong clinical instructor who made sure everything was clear and connected. I think having a strong clinical instructor made all the difference in the world.

I do believe that having a great clinical instructor who encourages you and motivates you in your first clinical is essential to the wellbeing of students.

Having peers in my clinical helped me cope with the stress.

Table 2. Emergent themes: Coping strategies used during the first semester $(n=36)$

\begin{tabular}{lll}
\hline \multirow{2}{*}{ Theme } & \multicolumn{2}{l}{$\begin{array}{l}\text { Number of Participants } \\
\text { Mentioned Theme (\%) }\end{array}$} \\
\cline { 2 - 3 } & N & \% \\
\hline Talking to classmates/instructor/advisor & 19 & 52.8 \\
Sleep & 11 & 30.6 \\
Exercise & 9 & 25 \\
Acceptance/Awareness/Balance & 8 & 22.2 \\
Socializing & 8 & 22.2 \\
Quiet Reflection/Meditation & 5 & 13.9 \\
Did Not Cope & 7 & 19.4 \\
\hline
\end{tabular}

Like pre-nursing school, self-care measures like sleep (n $=11,30.6 \%)$ and exercise $(n=9,25 \%)$ were also highly rated as well. Socializing was still cited by many $(n=8$, $22.2 \%$ ), with limitations due to time constraints. Students also mentioned that finding balance helped them to cope ( $\mathrm{n}$ $=7,19.4 \%)$. Quiet reflection and meditation $(\mathrm{n}=5,13.9 \%)$ was also cited as a coping mechanism in the first clinical rotation. Interestingly, some respondents stated they failed to cope well with stress during the first semester.

I didn't [cope]. It was honestly the most stressful semester of the program.

\subsection{Students' self-perceptions of coping with stress in clinical during later semesters}

For later semesters (after the first semester), respondents cited that coping was in the form of awareness/acceptance and balance $(n=24,66.7 \%)$. The following statements reflected this theme:

I was just better organized and knew more about what was expected.

You also become more familiar with the assignments given in conjunction with clinical, which can be stressful, but I feel after a year of clinical, I have a good understanding of what is expected in the assignments, so they are less stressful.

I feel much more comfortable asking questions than I did first semester, which has made me more confident and has made coping with the clinical experience much easier. 
Table 3. Emergent themes: Coping strategies used during later semesters $(\mathrm{n}=36)$

\begin{tabular}{lll}
\hline \multirow{2}{*}{ Theme } & \multicolumn{2}{l}{$\begin{array}{l}\text { Number of Participants } \\
\text { Mentioned Theme (\%) }\end{array}$} \\
\cline { 2 - 3 } & $\mathbf{N}$ & $\mathbf{\%}$ \\
\hline Acceptance/Awareness/Balance & 24 & 66.7 \\
Talking to classmate/instructor/advisor & 10 & 27.8 \\
Sleep & 8 & 22.2 \\
Cooking/Eating & 7 & 19.4 \\
Exercise & 5 & 13.9 \\
\hline
\end{tabular}

Student acceptance also included the student gaining comfort in knowing material during clinical. Discussing fears and issues with classmates, clinical instructors and advisors as a coping measure continued to be a constant theme $(\mathrm{n}=10$, $27.8 \%)$. Self-care, in the form of sleep $(\mathrm{n}=8,22.2 \%)$, cooking and eating $(\mathrm{n}=7,19.4 \%)$ and exercise $(\mathrm{n}=5,13.9 \%)$.

\subsection{Students missing clinical training time}

Among respondents, five reported health-related absences from clinical training time during first semester without subsequent absences in following semesters (see Table 4). For this subset of respondents, during first semester, two (40\%) reported they did not cope well, with one citing "no exercise at all". Two students (40\%) cited a need for self-care and reported in later semesters to proactively take "breaks" (associated with increased respondent confidence).

Table 4. Comparison of Coping Semester 1 to Later Semesters in Adaptive Students ( $\mathrm{n}=5$ )

\begin{tabular}{llll}
\hline Semester 1 Coping Technique & Number & Later Semester Coping Technique & Number \\
\hline Talking to classmates/instructor & 3 & Talking to classmates/instructor & 2 \\
Eating/Cooking & 1 & Eating/Cooking & 2 \\
No Coping & 2 & Taking a Break During Clinical & 2 \\
Sleep & 2 & Sleep & 2 \\
Quiet Reflection/Meditation & 2 & Feelings of Competence & 2 \\
No Exercise & 1 & Exercise & 1 \\
\hline
\end{tabular}

\section{DiscusSion}

This survey was part of a response by the pre-licensure nursing program to an unusual number of health-related events (including emergency department referrals) in a firstsemester nursing student cohort during first semester clinical training. Review of the results revealed some similar and some surprising results.

\subsection{Pre-nursing school coping}

Student reflection of coping strategies prior to nursing school were not surprising. Literature supports the use of these strategies once in nursing school. Adaptive physiological strategies such as exercise, sleep, and good eating are healthy strategies supported by literature. ${ }^{[13,14,32,33]}$ Coping via the use of socialization or social support is also a common strategy employed by students. ${ }^{[34-39]}$ Social support is a significant predictor in fostering positive psychological wellbeing. ${ }^{[39]}$ Awareness, acceptance and organization of all life activities is key and an important factor. Literature indicates that this is also an important factor for nursing students. ${ }^{[16,21]}$ Achieving good clinical/life balance ad organization was perceived as positive. Jan and Popescu ${ }^{[40]}$ found that providing organization or planning priorities was an adaptive coping behavior.

Meditation and quiet reflection, as a theme, was expressed Published by Sciedu Press as a strategy for individuals prior to entering nursing school. Meditation is a strategy that is recommended for use in nursing students. ${ }^{[19]}$ Uniquely, the use of media was a coping strategy mentioned as well. Students remarked that playing video games helped to decrease stress levels. This finding is supported by studies that show that the use of video games helps decrease stress in work environments. ${ }^{[41]}$

\subsection{First semester coping}

Since the first semester was the semester that most concerned the authors, findings were insightful. Many coping strategies were similar to pre-nursing school strategies (exercise, sleep), meditation, socializing and awareness/acceptance/organization. Lack of coping was not surprising. Many studies point to the first semester clinical experiences as being the most stressful. ${ }^{[1,42-44]}$ New students need to learn how to incorporate new educational schedules into their daily life; oftentimes, change in life habits (or coping) can be difficult. Students reporting high stress use inactive patterns to cope with stress. ${ }^{[45]}$ Consequently, student adaptation via connecting with peers and clinical instructors is key. This theme, "talking to classmates/instructor and advisor" was most prevalent. This differed from socializing with family and friends. This connection to classmates and instructors may occur during post conference, allowing for 
self-reflection and learning from the clinical experience. ${ }^{[21]}$ Guided reflection is a highly effective in reducing anxiety while developing trust between students and faculty. ${ }^{[46]}$ Faculty need to support students - especially in the first semester when they are prone to mistakes. ${ }^{[47]}$ Positive clinical faculty interaction is particularly useful in reducing student anxiety ${ }^{[15]}$ whereas negative clinical faculty interaction (e.g. impoliteness) can heighten anxiety. ${ }^{[48]}$ Journaling, as an asynchronous clinical assignment can provide self-reflection as well.

\subsection{Later semesters}

As students' progress, their confidence also improves. As reflected by student themes, the major theme reflected was "awareness/acceptance/organization". Students adapt, organize and cope as they learn to accept the structure of clinical. Student's desire to communicate to classmates/instructors or advisors diminishes as students become more familiar and competent. Students are no longer novices as student nurses.

\subsection{Student absence in the first semester}

For those who experienced an absence due to health concerns in the first semester, 2 of the 5 students expressed that they "did not cope" first semester. These students represent the population of nursing students that needed some assistance in coping. Uniquely, the use of self-care coping strategies, via breaks during clinical, was endorsed and utilized by two of these students. Principally, these students confirmed that the classroom/clinical toolkit was necessary.

\subsection{Limitations}

This study, which was an exploration of student coping, had initial limitations and constraints in data collection. Partici- pation was voluntary and anonymous as students. Comments were retrospective in nature. Respondents were recruited from students who were ending their designated training program. The enrollment rate was $25.2 \%$ of the class. A larger sampling of students would have been ideal.

Questions were generic in that specific areas of stress and maladaptive behavior were not specifically addressed (use of drugs, risk-taking behaviors, sexual activity, etc.). Quantitative responses (such as the number of hours of sleep per day, caloric or liquid intake, weight gained) were not collectable or were self-reported. Future evaluation of student stress is necessary.

\section{Conclusion}

The stress faced by first semester nursing students has been receiving increasing attention in the nurse education literature. Since incorporation of this toolkit, this first semester class has been held over 3 years with only three students leaving clinical due to student illness. One student had a documented chronic gastrointestinal absorptive disease and had been unable to eat the morning of clinical. Our own experience has provided an opportunity to examine the needs of first-semester students as they transition to clinical activities with respect to managing stress and this is a work in progress. As nursing education moves forward, there is need to formalize the support of students in managing stress as part of a comprehensive, multi-semester approach. Our toolkit, although simple has been enormously successful. Some other techniques may be incorporated as they "fit" in the clinical or academic environment.

\section{Conflicts of Interest Disclosure}

The authors declare that there is no conflict of interest.

\section{REFERENCES}

[1] Sheu S, Lin H, Hwang S. Perceived stress and physio-psychosocial status of nursing students during their initial period of clinical practice: the effect of coping behaviors. International Journal of Nursing Studies. 2002: 39(20): 165-175. https://doi.org/10.1016/S0 020-7489(01) 00016-5

[2] Shaban IA, Khater WA, Akhu-Zaheya LM. Undergraduate nursing students' stress sources and coping behaviours during their initial period of clinical training: a Jordanian perspective. Nurse Education in Practice. 2012; 12(4): 204-209. PMid:22281123 https: //doi.org/10.1016/j.nepr.2012.01.005

[3] McKenna L, Plummer V. Indonesian student nurses' perceptions of stressing clinical learning: phenomenological study. Journal of Nursing Education and Practice. 2013; 3(5): 56-65. https: //doi.org/10.5430/jnep.v3n5p56

[4] Suresh P, Matthews A, Coyne I. Stress and stressors in the clinical environment: A comparative study of fourth-year student nurses and newly qualified general nurses in Ireland. Journal of Clinical Nursing. 2012; 22(5-6): 70-779.

[5] Timmons F, Kaliszer M. Aspects of nurse education programmes that frequently cause stress in nursing students- fact finding sample survey. Nurse Education Today. 2002; 22(3): 3-11. PMid:12027601 https://doi.org/10.1054/nedt.2001.0698

[6] Jimenez C, Navai-Osorio PM, Diaz CV. Stress and health in novice and experienced nursing students. Journal of Advanced Nursing. 2010; 66(2): 442-455. PMid:20423427 https ://doi.org/10.1 $111 / j \cdot 1365-2648.2009 .05183 . x$

[7] Gibbons C, Dempster M, Moutray M. Stress and eustress in nursing students. Journal of Advanced Nursing. 2008; 61(3): 282-290. PMid:18197862 https://doi.org/10.1111/j.1365-2648. 20 $07.04497 . \mathrm{x}$

[8] Gibbons C. Stress, coping, and burn out in nursing students. In- 
ternational Journal of Nursing Studies. 2010; 47(10): 1299-1309. PMid:20359710 https://doi.org/10.1016/j.ijnurstu. 201 0.02 .015

[9] Deasy C, Coughlan B, Pironon J, et al. Psychological distress and coping amongst higher education students: A mixed method study. PLoS ONE. 2014; 9(12). PMid:25506825 https://doi .org/10 .1371/journal pone. 0115193

[10] Hensel D, Bradburn TC, Kelly A, et al. Student impressions of an art therapy class. Journal of Holistic Nursing. 2012; 30(4): 264-269. PMid:23007715 https://doi .org/10.1177/08980101124559 47

[11] Jones MC, Johnston DW. Reducing distress in first level and student nurses: A review of the applied stress management literature. Journal of Advanced Nursing. 2000; 32(1): 66-74. https: //doi.org/10.1046/j.1365-2648.2000.01421.x

[12] Murphy MC, Archer J. Stressors on a college campus: A comparasin 1985-1993. Journal of College Student Development. 1996; 37 : 20-28.

[13] Roux G, Dimarco N, Gu Y, et al. Eating, activity, and supportive environment (EASE) for nursing students. Nursing Forum. 2014; 49(1): 49-58. PMid:24456553 https ://doi .org/10.1111/nuf . 12047

[14] Blum CA. Practicing self-care for nurses: A nursing program initiative. Online Journal of Issues in Nursing. 2014; 19(3)

[15] Hutchinson TL, Janiszewski Goodin H. Nursing student anxiety as a context for Teaching/Learning. Journal of Holistic Nursing. 2013; 31(1): 19-24. PMid:23065057 https://doi .org/10.1177/0898 010112462067

[16] Riley JB, Yearwood EL. The effect of a pedagogy of curriculum infusion on nursing student well-being and intent to improve the quality of nursing care. Archives of Psychiatric Nursing. 2012; 26(5): 364373. PMid:22999032 https://doi.org/10.1016/j.apnu. 201 2.06 .004

[17] Turkeltaub PC, Yearwood EL, Friedmann E. Effect of a brief seated massage on nursing student attitudes toward touch for comfort care. Journal of Alternative and Complementary Medicine. 2014; 20(10): 792-799. PMid:25140587 https://doi.org/10.1089/acm.20 14.0142

[18] Hensel D, Laux M. Longitudinal study of stress, self-care, and professional identity among nursing students. Nurse Educator. 2014; 39(5): 227-231. PMid:24867076 https://doi .org/10.1097/NN E. 0000000000000057

[19] American Holistic Nurses Association. Holistic stress management is based on self-reflection and self care. Available from: http: //www . ahna.org/Home/Resources/Stress-Management

[20] American Nurses Association. 2017 is the year of the healthy nurse. Available from: http://www.nursingworld.org/MainMenuC ategories/ThePracticeofProfessionalNursing/2017-Y ear-of-Healthy-Nurse

[21] Yearwood E, Riley JB. Curriculum infusion to promote nursing student well-being. Journal of Advanced Nursing. 2010; 66(6): 1356-64. PMid:20546365 https://doi .org/10.1111/j.1365-2648.20 $10.05304 . x$

[22] Hensel D, Stoelting-Gettelfinger W. Changes in stress and nurse self-concept among baccaulaureate nursing students. Journal of Nursing Education. 2011; 50: 290-300. PMid:21323250 https: //doi.org/10.3928/01484834-20110131-09

[23] Scott E. Stress relief apps that can transform your life. 2018; Available from: https://www.verywellmind.com/stress-relie f-apps-that-can-transform-your-life-4147565

[24] Melnychuk MC, Dockree PM, O'Connell RG, et al. Coupling of respiration and attention via the locus coeru leus:Effects of medita- tion and pranayama. Psychophysiology. 2018; 1-17. PMid:29682753 https://doi.org/10.1111/psyp. 13091

[25] Harvard Medical School. Relaxation techniques: Breath control helps quell errant stress response. (April 13, 2018). Available from: https ://www.health.harvard.edu/mind-and-mood/rela xation-techniques-breath-control-helps-quell-erran t-stress-response

[26] Williams K. An exploratory study: Reducing nursing students stress levels facilitate perceived quality of patient care. Open Journal of Nursing. 2014; 4: 512-519. https://doi.org/10.4236/ojn. 20 14.47054

[27] Warren J, Smith N, Ashwell M. A structured literature review on the role of mindfulness, mindful eating and intuitive eating in changing eating behaviours: Effectiveness and associated potential mechanisms. Nutrition Research Reviews. 2017; 30(2): 272-283. PMid:28718396 https://doi.org/10.1017/S0954422417000 154

[28] Speck B. The effect of guided imagery upon first semester nursing students performing their first injections. Journal of Nursing Education. 2015; 29(8): 346-350.

[29] Spivey A. Lose sleep, gain weight: Another piece of the puzzle. Environmental Health Perspectives. 2010; 118(1): A28-A33. https://doi.org/10.1289/ehp.118-a28

[30] Braun V, Clarke V. Using thematic analysis in psychology. Qualitative Research in Psychology. 2006; 3: 77-101. https://doi .org/ 10.1191/1478088706qp063oa

[31] Côté L, Turgeon J. Appraising qualitative research articles in medicine and medical education. Medical Teacher. 2006; 27(1): 7175. PMid:16147774 https ://doi .org/10.1080/014215904000 16308

[32] Connor J. Finding time for healthy habits. NSNA Imprint. 2013; 27.

[33] Ashcraft PF, Gatto SL. Care-of-self in undergraduate nursing students: A pilot study. Nursing Education Perspectives. 2015; 36(4): 255-256. https://doi.org/10.5480/13-1241

[34] Kim J. Relationships between nursing practice stress and stress coping of nursing students in Korea. Journal of Digital Convergence. 2014; 12(2): 409-415. https://doi.org/10.14400/JDC. 2014. 12.2 .409

[35] Kim MR, Han SJ. Nursing students' emotional intelligence and coping strategies. Advanced Science and technology Letters. 2015; 88: 53-56.

[36] Reeve KL, Schumaker CJ, Yearwood EL, et al. Perceived stress and social support in undergraduate nursing students' educational experiences. Nurse Education Today. 2013; 33(4): 419-424. PMid:23246284 https://doi.org/10.1016/j.nedt.2012.11 .009

[37] Clark CM, Nguyen DT, Barbosa-Leiker C. Student perceptions of stress, coping, relationships and academic civility: A longitudinal study. Nurse Educator. 2014; 39(4): 170-174. PMid:24813939 https://doi.org/10.1097/NNE.0000000000000049

[38] Wolf L, Stidham AW, Ross R. Predictors of stress and coping strategies of US accelerated vs generic baccalaureate nursing students: An embedded mixed methods study. Nurse Education Today. 2015; 33(1): 201-205. PMid:25127928 https://doi.org/10.1016/j nedt.2014.07.005

[39] He FX, Turnbull B, Kirshbaum MN, et al. Assessing stress, protective factors and psychological well-being among undergraduate nursing students. Nurse Education Today. 2018; 68: 4-12. PMid:29870871 https://doi.org/10.1016/j.nedt.2018.05.013

[40] Jan LK, Popescu L. Israel's nursing students' stress sources and coping strategies during their first clinical experience in hospital wards A qualitative research. Revista de Asistenta Sociala. 2014. 
[41] Rupp MA, Sweetman R, Sosa AE, et al. Searching for Affective and Cognitive Restoration: Examining the Restorative Effects of Casual Video Game Play. Human Factors. 2017.

[42] Pagana KD. Stresses and threats reported by baccalaureate students in relation to an initial clinical experience. Journal of Nursing Educatio. 1988; 27(9): 418-424.

[43] Sharif F. Masoumi S. A qualitative study of nursing student experiences of clinical practice. BMC Nursing. 2005; 4: 6. PMid:16280087 https://doi.org/10.1186/1472-6955-4-6

[44] Alzayyat A, Al-Gamal E. A review of the literature regarding stress among nursing students during their clinical education. International Nursing Review. 2014; 61: 406-15. PMid:24902996 https://doi.org/10.1111/inr.12114
[45] Yildz Findik U, Ozbas A, Cavdar I, et al. Assessment of nursing students' stress levels and coping strategies in operting room practice. Nurse Practice Education. 2015; 15(3): 192-195. PMid:25801218 https://doi.org/10.1016/j.nepr.2014.11.008

[46] Beggs C, Shields D, Janiszewski-Goodin H. Using guided reflection to reduce test anxiety in nursing students. Journal of Holistic Nursing 2011.

[47] Zieber P, Williams B. The experience of nursing students who make mistakes in clinical. International Journal of Nursing Education Scholarship. 2015.

[48] Cook LL. Inviting teaching behaviors of clinical faculty and nursing students' anxiety. Journal of Nursing Education. 2005; 44: 156-161. 